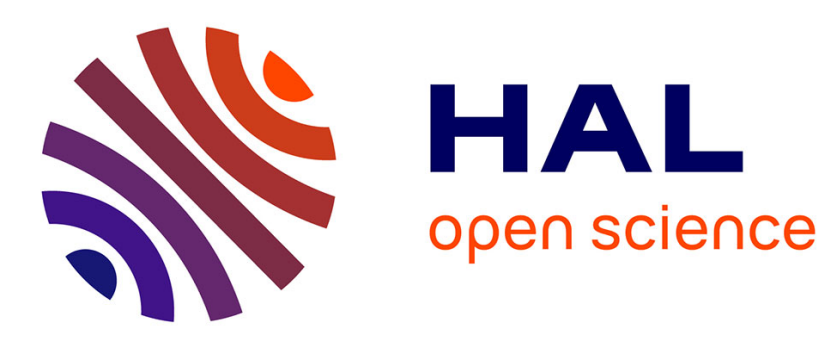

\title{
Load-bearing contribution of multi-walled carbon nanotubes on tensile response of aluminum
}

Hiroki Kurita, Mehdi Estili, Hansang Kwon, Takamichi Miyazaki, Weiwei Zhou, Jean-François Silvain, Akira Kawasaki

\section{- To cite this version:}

Hiroki Kurita, Mehdi Estili, Hansang Kwon, Takamichi Miyazaki, Weiwei Zhou, et al.. Load-bearing contribution of multi-walled carbon nanotubes on tensile response of aluminum. Composites Part A: Applied Science and Manufacturing, 2015, 68, pp.133-139. 10.1016/j.compositesa.2014.09.014 . hal-01078286

\section{HAL Id: hal-01078286 \\ https://hal.science/hal-01078286}

Submitted on 28 Oct 2014

HAL is a multi-disciplinary open access archive for the deposit and dissemination of scientific research documents, whether they are published or not. The documents may come from teaching and research institutions in France or abroad, or from public or private research centers.
L'archive ouverte pluridisciplinaire HAL, est destinée au dépôt et à la diffusion de documents scientifiques de niveau recherche, publiés ou non, émanant des établissements d'enseignement et de recherche français ou étrangers, des laboratoires publics ou privés. 


\section{Accepted Manuscript}

Load-bearing contribution of multi-walled carbon nanotubes on tensile response of aluminum

Hiroki Kurita, Mehdi Estili, Hansang Kwon, Takamichi Miyazaki, Weiwei Zhou, Akira Kawasaki, Jean-François Silvain

PII: S1359-835X(14)00287-5

DOI: http://dx.doi.org/10.1016/j.compositesa.2014.09.014

Reference: JCOMA 3722

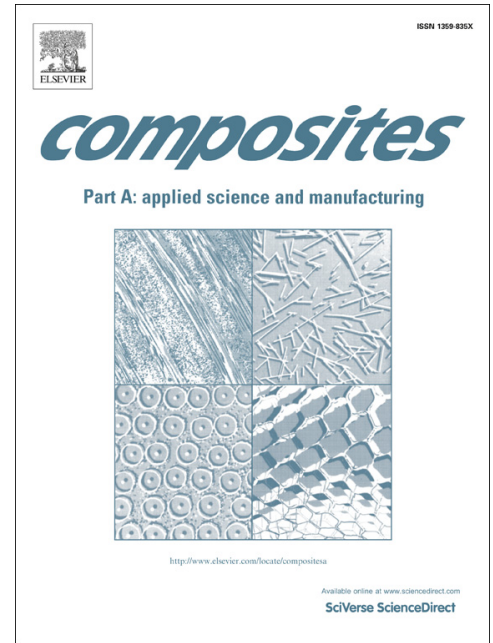

To appear in:

Composites: Part A

Received Date:

21 January 2014

Revised Date:

22 May 2014

Accepted Date:

12 September 2014

Please cite this article as: Kurita, H., Estili, M., Kwon, H., Miyazaki, T., Zhou, W., Kawasaki, A., Silvain, J-F., Load-bearing contribution of multi-walled carbon nanotubes on tensile response of aluminum, Composites: Part A (2014), doi: http://dx.doi.org/10.1016/j.compositesa.2014.09.014

This is a PDF file of an unedited manuscript that has been accepted for publication. As a service to our customers we are providing this early version of the manuscript. The manuscript will undergo copyediting, typesetting, and review of the resulting proof before it is published in its final form. Please note that during the production process errors may be discovered which could affect the content, and all legal disclaimers that apply to the journal pertain. 
Load-bearing contribution of multi-walled carbon nanotubes on tensile response of aluminum

Hiroki Kurita ${ }^{1 *}$, Mehdi Estili ${ }^{2}$, Hansang Kwon ${ }^{3}$, Takamichi Miyazaki ${ }^{4}$, Weiwei Zhou ${ }^{5}$, Akira Kawasaki $^{5}$ and Jean-François Silvain ${ }^{6}$

${ }^{1}$ DEN/DANS/DMN/SRMA/LTMEx, CEA Saclay, 91191 GIF sur YVETTE cedex, France

${ }^{2}$ International Center for Young Scientists, National Institute for Materials Science (NIMS), 1-2-1

Sengen, Tsukuba 305-0047, Japan

${ }^{3}$ Department of Materials System Engineering, Engineering Building 7, Pukyong National University, 365, Sinseon-ro, Nam-gu Busan 608-739, South Korea

${ }^{4}$ Technical Division, School of Engineering, Tohoku University, Sendai 980-8579, Japan.

${ }^{5}$ Department of Materials Processing, Graduate School of Engineering, Tohoku University, 6-6 Aoba, Aramaki, Aoba-ku, Sendai 980-8579, Japan

${ }^{6}$ Institut de Chimie de la Matière Condensée de Bordeaux (ICMCB-CNRS), 87 Avenue du Docteur Albert Schweitzer, 33608 Pessac Cedex, France

*Corresponding author

H.Kurita (Email: hiroki.kurita@live.com)

Abstract

We fabricated a uniformly dispersed and aligned multi-walled carbon nanotube reinforced aluminum matrix (Al-MWCNT) composite with minimal work hardening and without interfacial chemical compounds. In this paper, the direct load-bearing contribution of MWCNTs on the Al-MWCNT composite was investigated in detail for various volume fractions of MWCNTs. For up to 0.6 vol\% of MWCNTs, the ultimate tensile strength (UTS) of the Al-MWCNT composite increased with the conservation of the remarkable failure elongation of Al. These UTS values are consistent with shear lag model. We also observed an uncommon multi-wall-type failure of MWCNTs during the hot extrusion process. However, owing to the agglomeration of MWCNTs in the Al matrix, the UTS deviated significantly from the shear lag model and the remarkable failure elongation of $\mathrm{Al}$ decreased. The possibility of strengthening, without degrading ductility, was demonstrated by exploiting directly the load-bearing ability of individually and uniformly dispersed 
aligned MWCNTs.

\section{Introduction}

Inexpensive and mass-producible carbon nanotubes (CNTs) with their light weight, remarkable mechanical responses (e.g., multi-walled carbon nanotubes (MWCNTs) have young's modulus of $\sim 1$ TPa and strength of $200 \mathrm{GPa}$ with outstanding energy-absorbing capability and flexibility), and thermal/chemical stability $[1,2]$, could quite possibly be the perfect candidates for enhancing significantly the strength and stiffness of structural metal-based systems. They can improve energy efficiency in many industries that place demands on metals, such as the aerospace and automobile industries. Therefore, CNT reinforced aluminum (Al) matrix (Al-CNT) composite is expected to be a new high specific strength material, and powder metallurgical processing is attracting attention for its fabrication process for Al-CNT composite, which helps to avoid the excess reaction at Al/CNT interface. In this regard, powder metallurgical processing and mechanical properties of carbon nanotube (CNT) reinforced aluminum (Al) matrix (Al-CNT) composites have been investigated in recent years [3-7].

Processing of Al-CNT composites has faced great challenges in dispersing undamaged CNTs uniformly within the $\mathrm{Al}$ matrix and in achieving intimate $\mathrm{Al} / \mathrm{CNT}$ interfaces $[3,4,8]$. These two issues are vital prerequisites for the effective and realistic exploitation of the remarkable load-bearing capability of CNTs in a host metal matrix. In this regard, high-energy mechanical mixing/milling has been used widely [6] (despite dealing with lightweight, flexible, and highly entangled nanostructures with the high possibility of damaging the CNTs structure) to break the CNT aggregates, address the dispersion issue, and somehow improve the final densification and Al/CNT interfacial connections. The final consolidation of the mixed powders has been performed mainly using the powder metallurgical process, such as hot pressing and spark plasma sintering (SPS) [5]. In some studies, these have been followed by a secondary process, mainly hot extrusion, for possible CNT alignment with better densification [3,4,8]. Despite the strengthening reported in many of these studies, it is still not clear whether it was caused directly by the load transfer to the CNTs (via high interfacial interlocking resistance [9-12], which is caused either by an intimate clean interface or an interfacial impurity such as aluminum carbide $\left.\left(\mathrm{Al}_{4} \mathrm{C}_{3}\right)[3,4,13]\right)$, and/or the processing-induced work hardening of the $\mathrm{Al}$ matrix, and/or dislocation generation at the interfaces (due to different elastic moduli and coefficients of thermal expansion of the CNTs and the Al matrix) [14,15]. Furthermore, ultimately, the intrinsic ductility of the $\mathrm{Al}$ matrix became severely degraded. In brief, the direct load-bearing 
contribution of CNTs on the tensile response of the $\mathrm{Al}$ matrix, in a clean system in the absence of process-induced work hardening, dislocations, defects, and interfacial impurities (e.g., Al/CNT reaction products, etc.) has, as far as we know, never been demonstrated previously.

Recently, we succeeded in fabricating a fully dense Al-MWCNT composite by combining a colloidal mixing approach, and SPS followed by hot extrusion [8]. It seems that this Al-MWCNT composite has little residual strain, and contacted the Al/MWCNT interface directly without any interfacial chemical compound, and with the MWCNTs aligned mostly in the extrusion direction [8]. In this paper, we investigate the tensile response of this Al-MWCNT composite with various MWCNT volume fractions, and discuss the results with the use of transmission electron microscopy (TEM) micrographs and Kelly-Tyson's shear lag model [16]. This Al-MWCNT composite is a unique clean system, by which we could eventually demonstrate the contribution of load transfer to the MWCNTs (if any) on the tensile response of the Al, in the absence of processing-induced work hardening, and interfacial impurities $\left(\mathrm{Al}_{4} \mathrm{C}_{3}\right)$.

\section{Experimental details}

Gas-atomized Al powder (Ecka Granules Japan Co., Ltd.) with 99.85\% purity and average particle size of $6.19 \mu \mathrm{m}$, and pristine MWCNTs (Hodogaya Chemical Co., Ltd.) with average diameter of $50 \mathrm{~nm}$ and length of 10 20 $\mu \mathrm{m}$ were used as starting materials. The pristine MWCNTs were acid-treated in an ultrasonicated mixture of $\mathrm{H}_{2} \mathrm{SO}_{4} 98 \% / \mathrm{HNO}_{3} 68 \%(3: 1 \mathrm{v} / \mathrm{v})$ at $50{ }^{\circ} \mathrm{C}$ for 24 hours to break their agglomeration and to functionalize their surface with carboxylic groups. Predetermined amounts of Al powder and surface-functionalized MWCNTs were dispersed separately in ethanol by performing bath-sonication for three hours before the final mixing of their dispersions [8-12]. The MWCNT volume fraction of the final composites was controlled to be $0.2,0.4,0.6,0.8$, 1.0, 1.5, 2.0, 3.0, and 5.0 vol\%. Next, the dried mixed powder was consolidated into fully dense bulks by using SPS (Dr. Sinter S511, SPS Syntex Inc.). SPS was performed at $600{ }^{\circ} \mathrm{C}$ with a heating rate of $40{ }^{\circ} \mathrm{C} / \mathrm{min}$ for 20 minutes, under a compressive stress below $50 \mathrm{MPa}[3,8]$. The sintered bulks were then extruded in a $60^{\circ}$ conical die at $550{ }^{\circ} \mathrm{C}$ by a universal Instron tester $(\mathrm{UH}-500 \mathrm{kN} 1$, Shimadzu Corporation, Japan). The extrusion experiments were performed under the extrusion rate of 20 and speed of $1 \mathrm{~mm} / \mathrm{min}$.

The relative density of the Al-MWCNT composites was measured by the Archimedes principle. Microstructural characterization was performed using a field-emission scanning electron microscope 
(FE-SEM; JSM-6500F, JEOL, Japan) and a high-resolution transmission electron microscope (HR-TEM; HF-200EDX, Hitachi, Japan). For the TEM observations, the thin films of Al-MWCNT composites were prepared by the ion milling method (GATAN PIPS Model 691, Gatan Inc.) The crystallinities of pristine and functionalized MWCNTs were evaluated by Raman spectroscopy (SOLAR TII Nanofinder, Tokyo Instruments Co. Ltd., Japan). The grain size of Al was evaluated by electron back scatter diffraction method (EBSD; Orientation imaging microscope, TexSEM Laboratories Inc., Japan). The extruded composites were machined for tensile testing in accordance with the JIS Z 2201 standard. Tensile tests were conducted using the universal testing machine (AUTOGRAPH AG-I 50 kN, Shimadzu Co., Ltd., Japan) under the crosshead speed of $1 \mathrm{~mm} / \mathrm{min}$.

\section{Results and Discussion}

Table 1 shows the relative densities of the Al-MWCNT composites. In this study, Al powder and MWCNTs were mixed together by a colloidal process (not mechanical mixing such as the ball milling method) and SPS was carried out in solid state (i.e., the SPS temperature was lower than the melting point of $\mathrm{Al}$ ). Therefore, it seems that MWCNTs are not incorporated into $\mathrm{Al}$ particles and the relative density should be low. Nevertheless, the relative densities were higher than $97.5 \%$, despite the volume fractions from the MWCNTs. Although they decreased slightly when the volume fractions of MWCNTs were high. Thus, TEM obseryation was conducted to understand this phenomenon. Figure 1 shows the microstructure of the Al-MWCNT composite after SPS. MWCNTs were observed between two thin layers in the Al matrix. It has been reported that $\mathrm{Al}$ particles are covered with a thin alumina $\left(\mathrm{Al}_{2} \mathrm{O}_{3}\right)$ layer, which shows at the particle boundary of $\mathrm{Al}$ after SPS in Carbon fiber reinforced $\mathrm{Al}$ matrix composite [17]. Therefore, it seems that the observed thin layers are the $\mathrm{Al}_{2} \mathrm{O}_{3}$, and it shows that MWCNTs have intervened at Al particle boundaries, not inside of Al particles (see Figure 1b). This microstructure is consistent with the hypothesis mentioned above; SPS were carried out in a solid state in this study, thus MWCNTs are not incorporated into Al particles. However, the gaps at the Al particle boundaries created by the existence of the MWCNTs were filled up with Al. It has been reported that and the thin $\mathrm{Al}_{2} \mathrm{O}_{3}$ layer on $\mathrm{Al}$ particle can be fractured by the surface cleaning effect in SPS [17-20]. Moreover, Lalet et al. have suggested that the local temperature in SPS and reported the infiltration of $\mathrm{Al}$ into the triple point of $\mathrm{Al}$ particle boundaries through the fractured the $\mathrm{Al}_{2} \mathrm{O}_{3}$ layer [17]. Therefore, it seems that $\mathrm{Al}$ has transformed to liquid phase in SPS, and infiltrated into the gap through the fractured $\mathrm{Al}_{2} \mathrm{O}_{3}$ layer as can be seen by the white broken arrows in Figure 1b. This result shows 
clearly why a fully-dense Al-MWCNT composite can be fabricated by SPS, and supports the hypothesis we have proposed; the infiltration of momentarily appearing liquid phase $\mathrm{Al}$ into defects on the surface of the MWCNTs, and the formation of directly contacted Al/MWCNT interfaces [8]. It was observed that there was no chemical compound (i.e., aluminum carbide $\left(\mathrm{Al}_{4} \mathrm{C}_{3}\right)$ ) at the $\mathrm{Al} / \mathrm{MWCNT}$ interfaces, although $\mathrm{Al}_{4} \mathrm{C}_{3}$ could easily be formed at the directly contacted $\mathrm{Al}$ with the defects on the surface of the MWCNTs. Therefore, it seems that the appearance time of the liquid phase of $\mathrm{Al}$ is insufficient for interfacial reaction.

The relative densities achieved $99.9 \%$ after hot extrusion on each volume fraction of the MWCNTs (see Table 1). Figure 2 shows the microstructure of the Al-MWCNT composite after hot extrusion. The MWCNTs were individually and uniformly dispersed in the Al matrix without contact among them, and they were mostly aligned to the extrusion direction. Then, the result of EBSD mapping revealed the grain size of $\mathrm{Al}$ was not changed between before and after hot extrusion as shown in Figure 3. This result clearly shows that hot extrusion process does not propose the increase in the mechanical properties of Al-MWCNT composite by the refinement of the grain size, and provides further support for the hypothesis, which we have suggested; Al matrix is not mechanically enhanced because the surface hardness of Al-MWCNT composite is constant before and after hot extrusion [8]. By virtue of the incorporation of the MWCNTs in the Al particles, caused by the flow of the $\mathrm{Al}$ during hot extrusion, the $\mathrm{Al} / \mathrm{MWCNT}$ interface was intimate and with direct contact and without an intermediate $\mathrm{Al}_{2} \mathrm{O}_{3}$ layer. Furthermore, no $\mathrm{Al}_{4} \mathrm{C}_{3}$ was observed at the interface. The TEM micrograph and result of EBSD mapping indicate that this Al-MWCNT composite can demonstrate the load-bearing contribution of MWCNTs on the tensile response of aluminum.

Figure 4 shows the Raman spectra of the MWCNTs at different stages of processing. According to the $\mathrm{I}_{\mathrm{D}} / \mathrm{I}_{\mathrm{G}}$ ratios in the Raman spectra, the SPS and hot extrusion processes did not increase the defects on the starting COOH-functionalized MWCNTs surfaces. Cho et al. have reported that MWCNTs still retain considerably their high crystalline integrity while the initial functionalization process could have caused some damage to the pristine MWCNTs surfaces, as characterized by the increase in the $I_{D} / I_{G}$ ratio and the evolution of the $\mathrm{D}^{\prime}$ peak near $1620 \mathrm{~cm}^{-1}$ [21]. This conservation of high crystalline integrity in MWCNTs suggests that the MWCNTs maintain their remarkable mechanical properties, comparable to pristine MWCNTs, after SPS and hot extrusion [11,12,22,23].

Further TEM observations of the extruded bulks resulted in a striking observation, as shown in 
Figure 5. Some MWCNTs experienced a generally uncommon multi-wall-type failure during the extrusion process $[11,12]$. It seemed that the inner wall of the MWCNT was pulled out from the outer wall; however, this inner wall still contacted the Al. This highly energy-dissipating multi-wall-type failure was first observed by Estili et al. [11,12] in a MWCNT reinforced $\mathrm{Al}_{2} \mathrm{O}_{3}$ ceramic matrix composite during fracture at room temperature, and attributed it to the formation of in-wall irregularities in the MWCNTs structure (leading to strong inter-wall shear resistance) due to misfit radial compressive stresses applied from the ceramic matrix. Therefore, it seems that this fracture is caused in the hot extrusion process and not during SPS. To the best of our knowledge, the realization of such multi-wall-type failures during the processing of a metal matrix composite (with comparatively low elastic modulus) has not been reported previously while it has been reported that the pulling out of MWCNTs, which is believed to be occurred as a result of a multi-walled failure, which is on the fracture surface of the Al-MWCNT composite and fabricated by hot extrusion [7]. Note that this unusual feature could not be due to permanent radial deformation of the MWCNTs during the extrusion (MWCNTs are extremely soft and energy absorbing in the radial direction [11, 12]), as according to Huang et al. [24], it requires a very high temperature of nearly $2000{ }^{\circ} \mathrm{C}$.

In general, MWCNTs must break only from their outermost walls, which carry the entire load; the common one-wall failure type is due to weak van der Waals-based inter-wall interactions, which makes the inner walls totally useless [11,12]. However, the disarray of graphite structure in concentric MWCNT walls (see Figure 6) implies that the radial compressive stress has been applied in hot extrusion. Therefore, it seems that the applied tensile load to Al matrix has been transferred to not only the outermost wall, but also to the inner walls of the MWCNT, and the hot extrusion process can contributes to enhancing the inter-wall interactions and enable load distribution.

On the other hand, the realization of the multi-wall-type failure suggests that the shear resistance at the Al/MWCNT interfaces (in SPSed Al-MWCNT composite), which determines how effectively the load is transferred to the MWCNTs, is higher than the fracture strength of MWCNTs, even if many walls carry the load simultaneously; i.e., the highest load transfer to the MWCNTs is possible in the Al-MWCNT composites (until they eventually break), despite having clean physical interfaces (no interfacial $\mathrm{Al}_{4} \mathrm{C}_{3}$ ). Perhaps, only strong mechanical interlocking of the MWCNTs surface defects and the $\mathrm{Al}$ matrix is responsible for such promising high interfacial shear resistance.

Figure 7 shows the typical stress-strain responses of the Al-MWCNT 0.6 vol\% composite, SPSed and hot extruded (HEed) Al, and as-cast Al (A1050). The addition of uniformly dispersed 
MWCNTs, even in very low concentrations of $0.6 \mathrm{vol} \%$ of MWCNTs, improved considerably the ultimate tensile strength, while preserving a remarkable $\sim 24 \%$ failure elongation, as we have reported previously [8]. It seems that this remarkable failure elongation has been obtained because the $\mathrm{Al}$ matrix is not enhanced by such as the refinement of $\mathrm{Al}$ grain size and work hardening; it is implied that the increase in ultimate tensile strength of Al-MWCNT composite has been obtained by the addition of MWCNTs. This outstanding ductility makes the strengthened Al-MWCNT composite superior to other $\mathrm{Al}$ alloys (e.g., duralumin, etc.) enhanced based on traditional dislocation generation mechanisms [25] with greatly reduced ductility. It should be noted that the tensile property of SPSed and HEed Al is indeed expected to be superior to that of as-cast $\mathrm{Al}$, because $\mathrm{Al}$ prepared by a powder metallurgical process contains some $\mathrm{Al}_{2} \mathrm{O}_{3}$ particles, which could improve the tensile properties [14].

Figures 8 and 9 show the effect of the volume fraction of MWCNTs on the UTS, and failure elongation of the fully dense Al-MWCNT composites, respectively. Up to $0.6 \mathrm{vol} \%$, the UTS increased proportionally with the volume fraction of MWCNTs, reaching the maximum value of $\sim 165 \mathrm{MPa}$, while large and comparable failure elongations, similar to the SPSed and HEed Al, were realized. However, beyond $0.6 \mathrm{vol} \%$, the UTS values appeared to be saturated and independent of the concentration (typically $\sim 160-170 \mathrm{MPa}$ ). SEM and TEM observation revealed that MWCNTs were agglomerated in Al-MWCNT 5.0 vol\% composite (see Figure 10). This observed agglomeration of MWCNTs implies that the individual and uniform dispersion of MWCNTs in Al matrix is lost beyond 0.6 vol\% and MWCNTs with more than 0.6 vol\% do not contact with Al matrix (i.e. they do not bear the applied tensile load). However, it seems that the MWCNTs, which are intimately contacted with $\mathrm{Al}$ matrix $(\sim 0.6 \mathrm{vol} \%$ of MWCNTs), effectively bear the applied tensile load regardless of total volume fraction of MWCNTs. Therefore it seems that the UTS values of Al-MWCNT composite seem to be saturated. In contrast, the failure elongations decreased with the volume fraction of MWCNTs. The reason behind the significant decrease of the failure elongations, for instance, in Al-MWCNT 5.0 vol\% composite $(\sim 11 \%)$, could be the agglomeration of the MWCNTs, acting as defects. Note that considering the rather large particle size (low surface-to-volume ratio) of the existing Al powder, there is a critical volume fraction of MWCNTs (here $\sim 1$ vol\%), below which the agglomeration could be avoided; i.e., at concentrations above this limit, there would be insufficient surface to host the dispersed MWCNTs, which leads to their re-agglomeration.

In general, fiber-reinforced composite materials can be enhanced by a combined mechanism of 
grain refinement, dislocation strengthening, and load bearing if the aspect ratio of CNTs and interfacial bonding strength are sufficient [14,16]. Concerning this Al-MWCNT composite, it seems that the enhancement of mechanical properties of Al-MWCNT composite by the refinement of the grain size of $\mathrm{Al}$ is remained minimal while there must be little residual strain in the $\mathrm{Al}$ matrix after hot extrusion [8]. Furthermore, George et al. have reported that the strengthening in Al-MWCNT composites can be explained effectively mainly by load bearing and the shear lag model [14]. Therefore, to examine the acceptability of these experimental UTS values and to clarify the main strengthening mechanism of this Al-MWCNT composite, we estimated the theoretically expected UTS values for this Al-MWCNT composite using the shear lag theory. The UTS in this model, $Q$ is given by Kelly-Tyson's equations as follows [16]:

$$
\begin{gathered}
\sigma_{c}=\sigma_{f} V_{f}\left(1-\frac{\ell_{c}}{2 \ell}\right)+\sigma_{m}{ }^{\prime}\left(1-V_{f}\right)\left(\ell \geq_{c}\right) \cdots(1) \\
\sigma_{c}=V_{f} \frac{\tau_{y} \ell}{d}+\sigma_{m}\left(1-V_{f}\right)_{\left(\ell<\ell_{c}\right)} \cdots(2)
\end{gathered}
$$

where $\phi$ is the tensile strength of the fibers (here MWCNTs); $\omega_{r}^{\prime}$ is the stress on the Al matrix when the MWCNTs ultimately fail in the composite; $\tau$ is the shear yield stress of the Al matrix (almost equal to half the tensile yield stress of the Al matrix); $V_{f}$ is the volume fraction of MWCNTs; $d$ is the average diameter of the MWCNTs; $\ell$ is the average length of the MWCNTs; and $\ell_{c}$ is the critical MWCNT length, as described below.

The relationship between length $\ell$ and the critical length $\ell_{c}$ determines which equation is to be used. To use these equations, however, the following assumption must be made; the fiber reinforcements with regular separations and perfect contact with the matrix are aligned to a single direction. In this Al-MWCNT composite, the MWCNTs with intimate interfaces with the matrix are fixed between same sized Al particles and effectively aligned to the extrusion direction (parallel to the loading direction) [8]; therefore, this assumption is largely satisfied for this Al-MWCNT composite.

The critical length $\ell_{c}$ indicates the minimum length required for a perfect load transfer, such that the MWCNTs could ultimately be loaded up to their UTS values and fail during loading of the 
composite. Therefore, loading of the Al-MWCNT composite involves failure of the MWCNTs (maximum load transfer) when $\ell \geq \ell_{c}$. Under this condition, higher UTS values are indeed expected for the composite. This critical fiber length, $\ell_{c}$ is given by equation (3):

$$
\ell_{c}=\frac{d c_{f}}{2 \tau_{y}} \cdots(3)
$$

The tensile strength of the MWCNTs $\phi$ is taken as $82 \mathrm{GPa}$, which is that of a surface-defective MWCNT experimentally and accurately measured by Peng et al. [26]. This surface-defective MWCNT is the most similar in structure and property to the surface-acid treated MWCNTs. The average diameter of the MWCNTs $d$ is considered as $50 \mathrm{~nm}$. $\tau_{y}$ is the shear yield stress of the Al matrix. Kelly has been reported that $\tau_{y}$ can be assumed the half of tensile yield stress of the Al matrix [27], while it is difficult to investigate $\tau_{y}$ experimentally. In this study, $\tau_{y}$ is assumed $41 \mathrm{MPa}$, which is half the $82 \mathrm{MPa}$ tensile yield stress of the Al matrix (see Figure 7). Therefore, the critical length of the MWCNTs $\left(\ell_{c}\right)$ is calculated at $50 \mu \mathrm{m}$ by equation (3). Thus, in this Al-MWCNT composite, we have $\ell$ $<\ell_{c}$, considering the value of $\ell$ is $10 \sim 20 \mu \mathrm{m}$. When $\ell<\ell_{c}$, the applied tensile load to Al matrix is not transferred to the point of the tensile fracture strength of MWCNTs; Al-MWCNT composite is finally fractured because of the ductile failure of Al matrix while MWCNTs bear a certain level of the applied tensile load. This result proposes the reason why the failure elongation of this Al-MWCNT composite (especially below 1 vol\% MWCNTs) is very large and comparable with pure Al.

The comparison between the experimental and theoretical UTS values of the Al-MWCNT composites, which were calculated by equation (2), is shown as the gray area in Figure 8 . The $\ell$ of 10 $\mu \mathrm{m}$ and $20 \mu \mathrm{m}$ achieve the lower and upper limits of the theoretical UTS values, respectively. The experimental UTS values are consistent with the theoretical values in composites with up to 0.6 vol\% of MWCNTs. This result suggests that the promising load-bearing capability of the MWCNTs is exploited effectively during loading. The slight deviation could be due to some slight slipping of the MWCNTs during loading, which is indeed expected. Note that the interfaces in this Al-MWCNT composite are physical (no interfacial compound such as $\mathrm{Al}_{4} \mathrm{C}_{3}$, etc.); thus, some slight slipping of the MWCNTs seems possible during loading, which prevents perfect load transfer. This phenomenon 
suggests that the formation of $\mathrm{Al}_{4} \mathrm{C}_{3}$ crystals at the $\mathrm{Al} / \mathrm{MWCNT}$ interface reinforces interfacial strength, and increases the tensile strength of the Al-MWCNT composite [3,13]. It seems that the large deviation of the experimental and theoretical UTS values (saturation of the experimental values) at the volume fraction of MWCNTs beyond $0.6 \mathrm{vol} \%$, is attributed to the agglomeration of the MWCNTs (see Figure 10), preventing formation of intimate interfaces with the matrix, which is a prerequisite for load transfer. The agglomerated MWCNTs cannot receive and carry the applied load (no interface exists for the load transfer), and instead act like defects and degrade the remarkable failure elongation of the composites, as shown in Figure 9.

\section{Conclusion}

The fully-dense Al-MWCNT composites were fabricated with minimal work hardening and without an interfacial chemical compound by SPS followed by hot extrusion. TEM micrographs revealed the densification mechanism of this Al-MWCNT composite and the formation mechanism of the directly contacted Al/MWCNTs during SPS. After hot extrusion, it was observed that the individually and uniformly dispersed MWCNTs were aligned in the Al matrix, i.e., this Al-MWCNT composite can demonstrate a load-bearing contribution of the MWCNTs on the tensile response of aluminum. Furthermore, the multi-wall fracture of the MWCNTs was observed. This fracture indicates that the radial compressive stress is applied to MWCNTs in hot extrusion, and implies that the hot extrusion process can enhance the inter-wall interactions and enable load distribution.

The values of UTS of the Al-MWCNT composites increased proportionally with the volume fraction of the MWCNTs, reaching the maximum value of $\sim 165 \mathrm{MPa}$ with the conservation of remarkable failure elongation of $\mathrm{Al}$ up to $0.6 \mathrm{vol} \%$ of the MWCNTs. The experimental UTS values of the Al-MWCNT composites were consistent with the theoretical UTS values estimated by the shear lag model. The slight deviation of the UTS values on the Al-MWCNT composites, which have no interfacial chemical compound $\left(\mathrm{Al}_{4} \mathrm{C}_{3}\right)$, suggests that there is the possibility of increasing further the tensile property of $\mathrm{Al}-\mathrm{MWCNT}$ composites by the formation of $\mathrm{Al}_{4} \mathrm{C}_{3}$ at the $\mathrm{Al} / \mathrm{MWCNT}$ interface.

However, the severe agglomeration of the MWCNTs, which was observed beyond concentrations of $0.6 \mathrm{vol} \%$ of MWCNTs, caused the saturation of the UTS values and the decrease of failure elongations of the Al-MWCNT composites. Nevertheless, it was indicated paradoxically that the essential tensile property of MWCNTs can be brought out if the MWCNTs are individually and uniformly dispersed in the Al matrix. Therefore, the establishment of an effective mixing 
method for MWCNTs and Al powder could lead to further increases in the tensile property of Al-MWCNT composites.

\section{References}

[1] Ogata S, Shibutani Y. Ideal tensile strength and band gap of single-walled carbon nanotubes. Phys. Rev. B 2003;68:165409.

[2] Yu MF, Lourie O, Dyer MJ, Moloni K, Kelly TF, Ruoff RS. Strength and breaking mechanism of multiwalled carbon nanotubes under tensile load. Science 2000;287:637-640.

[3] Kwon H, Estili M, Takagi K, Miyazaki T, Kawasaki A. Combination of hot extrusion and spark plasma sintering for producing carbon nanotube reinforced aluminum matrix composites. Carbon 2009;47:570-577.

[4] Kwon H, Kawasaki A. Extrusion of spark plasma sintered aluminum-carbon nanotube composites at various sintering temperatures. J. Nanosci. Nanotech. 2009;1(9):6542-6548.

[5] Bakshi SR, Lahiri D, Agarwal A. Carbon nanotube reinforced metal matrix composites. Int. Mater. Rev. 2010;55:41-64.

[6] Choi HJ, Kwon GB, Lee GY, Bae DH. Reinforcement with carbon nanotubes in aluminum matrix composites. Scr. Mater. 2008;59:360-363.

[7] Esawi AMK, Morsi K, Sayed A, Gawad AA, Borah P. Fabrication and properties of dispersed carbon nanotube - aluminum composites. Mater. Sci. Eng. A 2009;508:167-173.

[8] Kurita H, Kwon H, Estili M, Kawasaki A. Multi-Walled carbon nanotube-aluminum matrix composites prepared by combination of hetero-agglomeration method, spark plasma sintering and hot extrusion. Mater. Trans. 2011;52(10):1960-1965.

[9] Estili M, Sakka Y, Kawasaki A. Unprecedented simultaneous enhancement in strain tolerance, toughness and strength of $\mathrm{Al} 2 \mathrm{O} 3$ ceramic by multiwall type failure of a high loading of carbon nanotubes. Nanotech. 2013;24:155702

[10] Estili M, Kawasaki A, Sakka Y. Highly concentrated 3D macrostructure of individual carbon nanotubes in a ceramic environment. Adv. Mater. 2012;24:4322-4326.

[11] Estili M, Kawasaki A. Engineering strong intergraphene shear resistance in multi-walled carbon nanotubes and dramatic tensile improvements. Adv. Mater. 2010;22:607-610.

[12] Estili M, Kawasaki A, Pittini-Yamada Y, Utke I, Michler J. In situ characterization of tensile-bending load bearing ability of multi-walled carbon nanotubes in alumina-based 
nanocomposites. J. Mater. Chem. 2011;21:4272-4278.

[13] Kwon H, Kurita H, Leparoux M, Kawasaki A. Carbon nanofiber reinforced aluminum matrix composite fabricated by combined process of spark plasma sintering and hot extrusion. J. Nanosci. Nanotech. 2011;11:4119-4126.

[14] George R, Kashyap KT, Rahul R, Yamdagni S. Strengthening in carbon nanotube/aluminum (CNT/Al) composites. Scr. Mater. 2005;53:1159-1163.

[15] Arsenault RJ, Shi N. Dislocation generation due to differences between the coefficients of thermal expansion. Mater. Sci. Eng. 1986;81:175-187.

[16] Kelly A, Tyson WR. Tensile properties of fibre-reinforced metals: copper/tungsten and copper/molybdenum. J. Mech. Phys. Solid, 1965;13:329-350.

[17] Lalet G, Kurita H, Miyazaki T, Kawasaki A, Silvain J-F. Microstructure of a carbon fiber-reinforced aluminum matrix composite fabricated by spark plasma sintering in various pulse conditions. J. Mater. Sci. 2014;49:3268-3275

[18] Xie G, Ohashi O, Chiba K, Yamaguchi N, Song M, Furuya K, Noda T. Frequency effect on pulse electric current sintering process of pure aluminium powder. Materials Science and Engineering A 2003;359:384-390.

[19] Omori M. Sintering, consolidation, reaction and crystal growth by the spark plasma system (SPS). Materials Science and Engineering A 2000;287:183-188.

[20] Lalet G, Kurita H, Heintz J-M, Lacombe G, Kawasaki A, Silvain J-F. Thermal expansion coefficient and thermal fatigue of discontinuous carbon fiber-reinforced copper and aluminum matrix composites without interfacial chemical bond. J. Mater. Sci. 2014;49:397-402.

[21] Cho S, Kikuchi K, Kawasaki A. Radial followed by longitudinal unzipping of multiwalled carbon nanotubes. Carbon 2011;49:3865-3872.

[22] Tuinstra F, Koenig JL. Raman spectrum of graphite. J. Chem. Phys. 1970;35:1126.

[23] Nakamizo M, Honda H, Inagaki M. Raman spectra of ground natural graphite. Carbon 1978;16:281-283.

[24] Huang JY, Chen S, Wang ZQ, Kempa K, Wang YM, Jo SH, Chen G, Dresselhaus MS, Ren ZF. Superplastic carbon nanotubes. Nature 2006;439:281.

[25] Pai BC, Ray S, Prabhakar KV, Rohatgi PK. Fabrication of aluminiumalumina (magnesia) particulate composites in foundries using magnesium additions to the melts. Mater. Sci. and Eng. 1976;24(1):31. 
[26] Peng B, Locascio M, Zapol P, Li S, Mielke SL, Schatz GC, Espinosa HD. Measurements of near-ultimate strength for multiwalled carbon nanotubes and irradiation-induced crosslinking improvements. Nature Nanotech. 2008;3:626-631.

[27] Kelly A, Macmillan NH. Strong Solids. 3rd ed. Oxford: Science Publications, 1966. p. 264.

Figure captions

Figure 1. TEM micrograph of Al-MWCNT 0.6 vol\% composite fabricated by SPS: (A) overview, and (B) high-magnification images.

Figure 2. TEM micrograph of Al-MWCNT 0.6 vol\% composite fabricated by SPS followed by hot extrusion.

Figure 3. EBSD mappings of (a) Pure Al before hot extrusion, (b) Pure Al after hot extrusion in extrusion direction, (c) Pure Al after hot extrusion in cross-sectional direction, (d) Al-MWCNT 0.6 vol\% composite before hot extrusion, (e) Al-MWCNT 0.6 vol\% composite after hot extrusion in extrusion direction and (f) Al-MWCNT 0.6 vol\% composite after hot extrusion in cross-sectional direction.

Figure 4. Raman spectra of the MWCNTs at different stages of processing.

Figure 5. TEM micrograph of the multi-wall failure of MWCNTs in Al-MWCNT 0.6 vol\% composite.

Figure 6. TEM micrograph of the crystal structure of MWCNTs to cross-section direction in Al-MWCNT 0.6 vol\% composite.

Figure 7. Typical stress-strain curve of as-cast Al (A1050), the SPSed and hot extruded Al, and Al-MWCNT 0.6 vol\% composites. 
Figure 8. UTS values versus the volume fraction of MWCNTs; UTS values estimated by Kelly-Tyson's equation (indicated as gray area).

Figure 9. Failure elongation of Al-MWCNT composites versus the volume fraction of MWCNTs.

Figure 10. Agglomeration of MWCNTs in Al-MWCNT 5.0 vol\% composite: (A) SEM image of the fracture surface, (B) a TEM image.

Table captions 

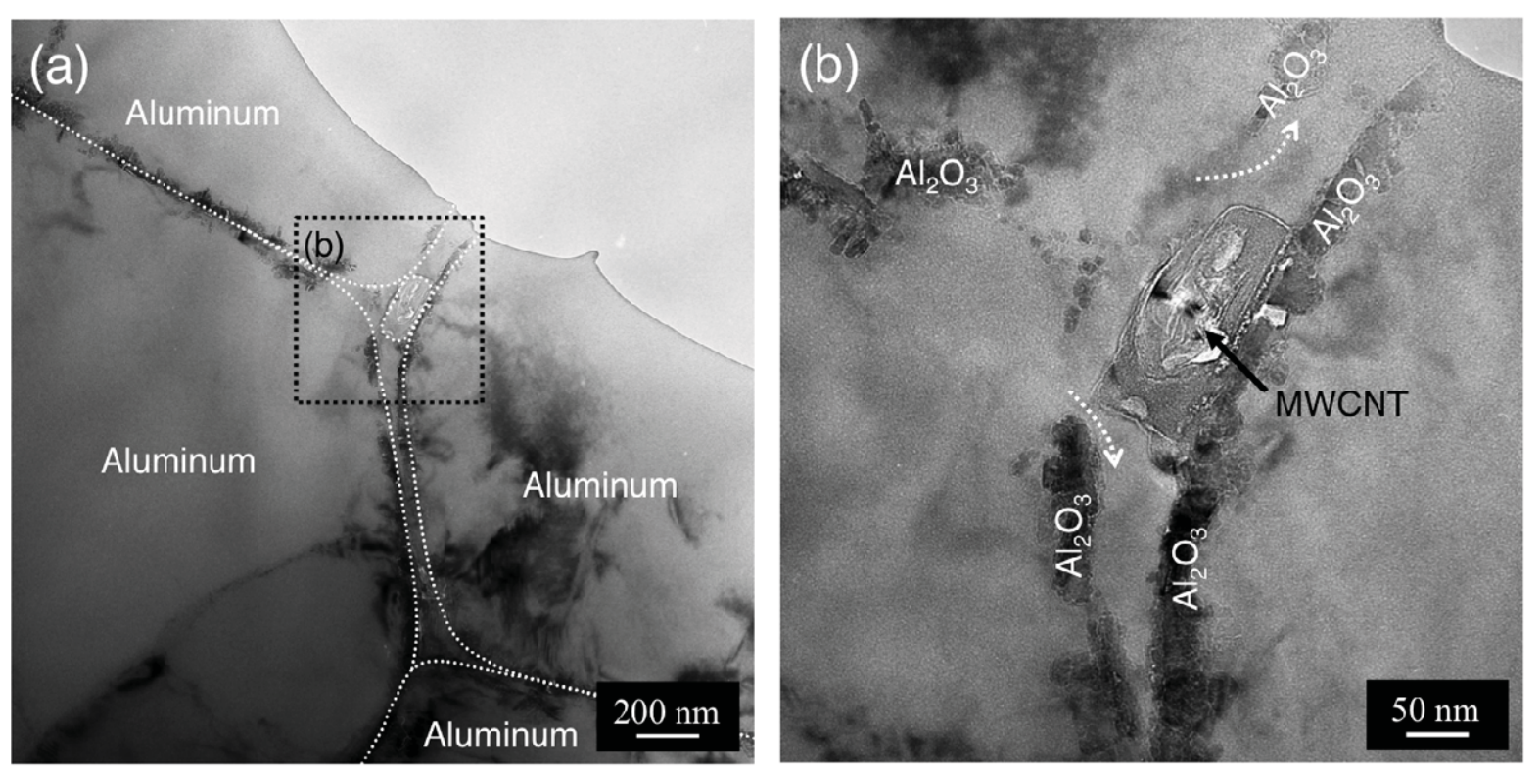


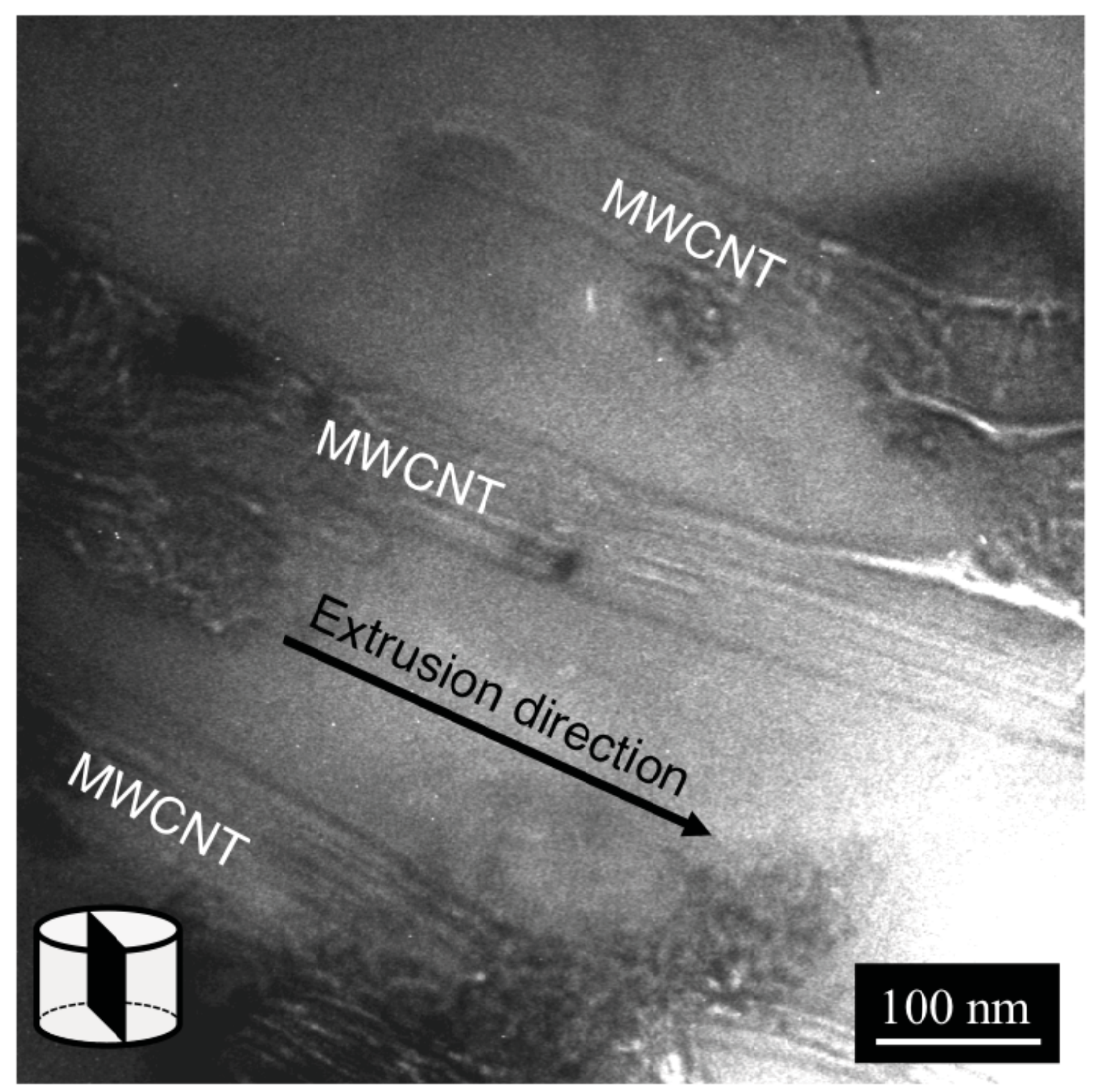



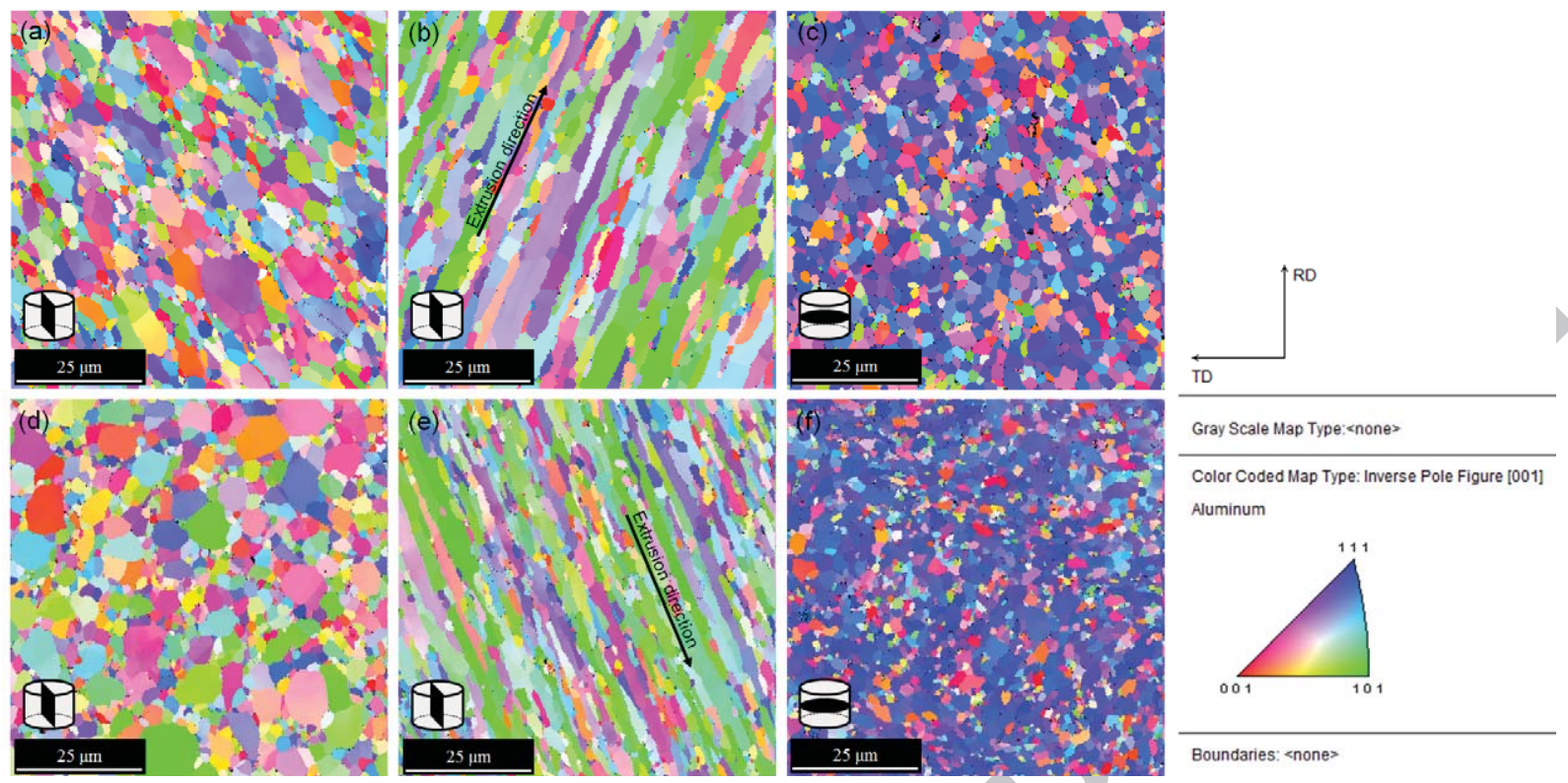

Boundaries: <nones 


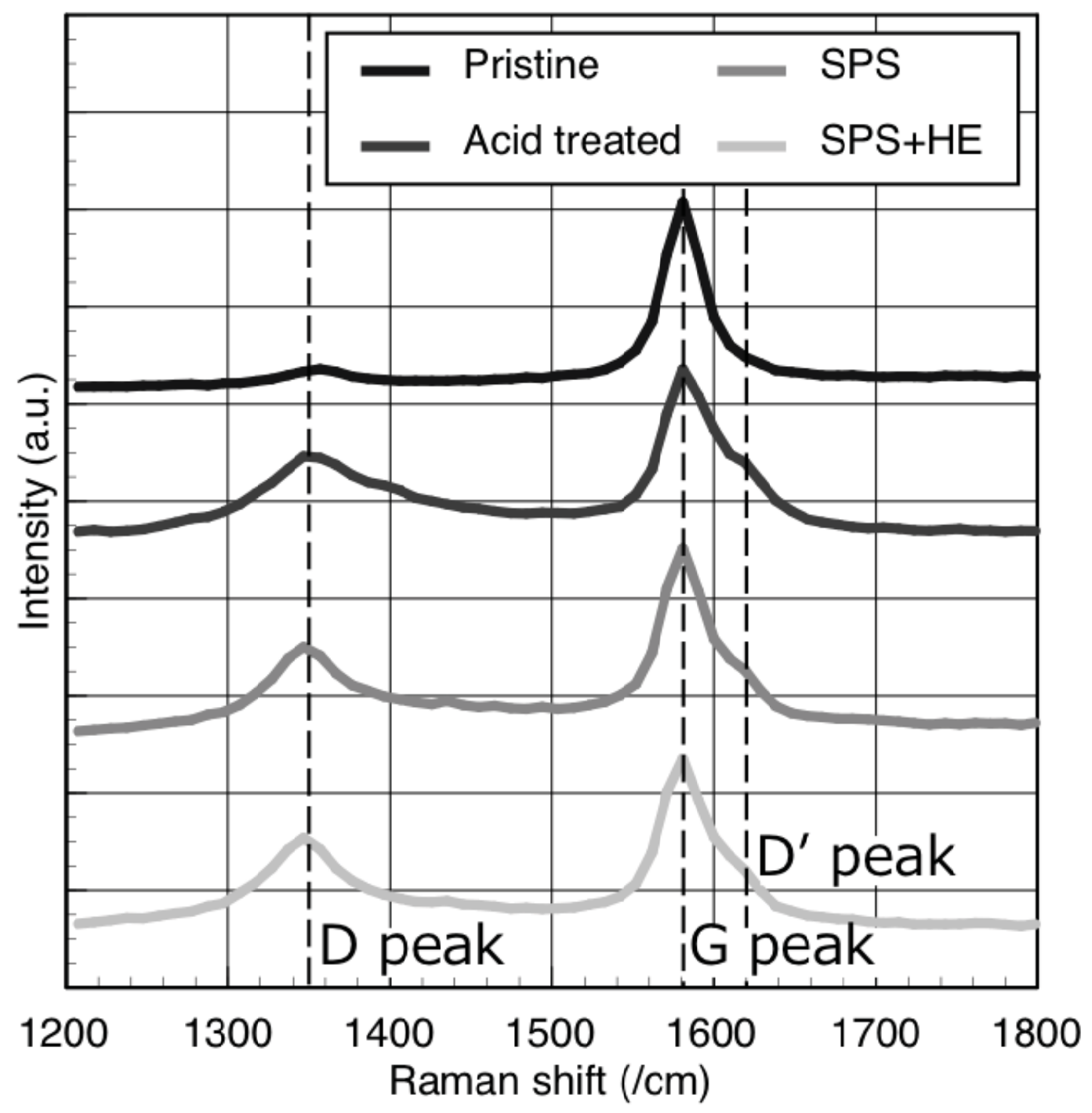



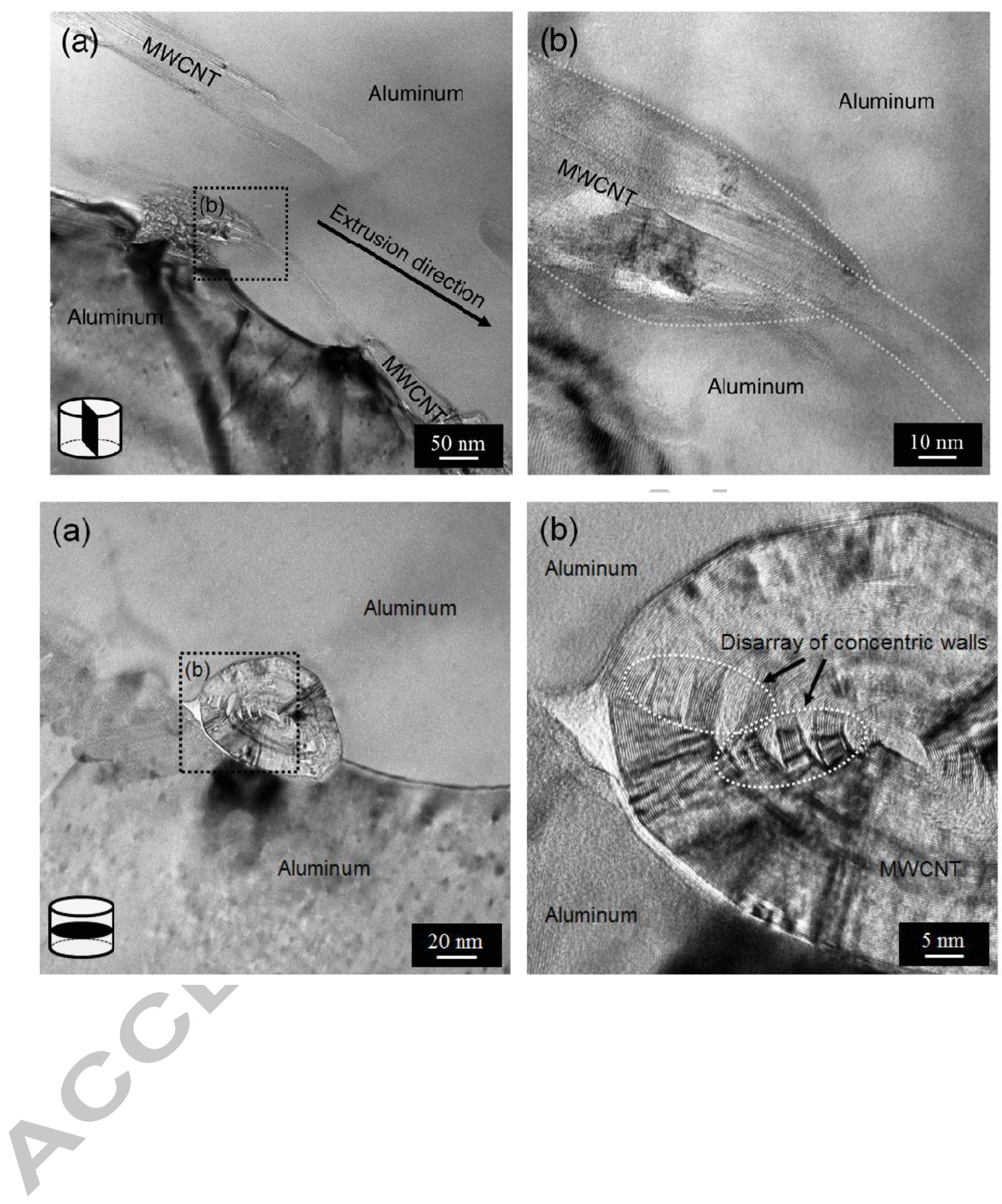


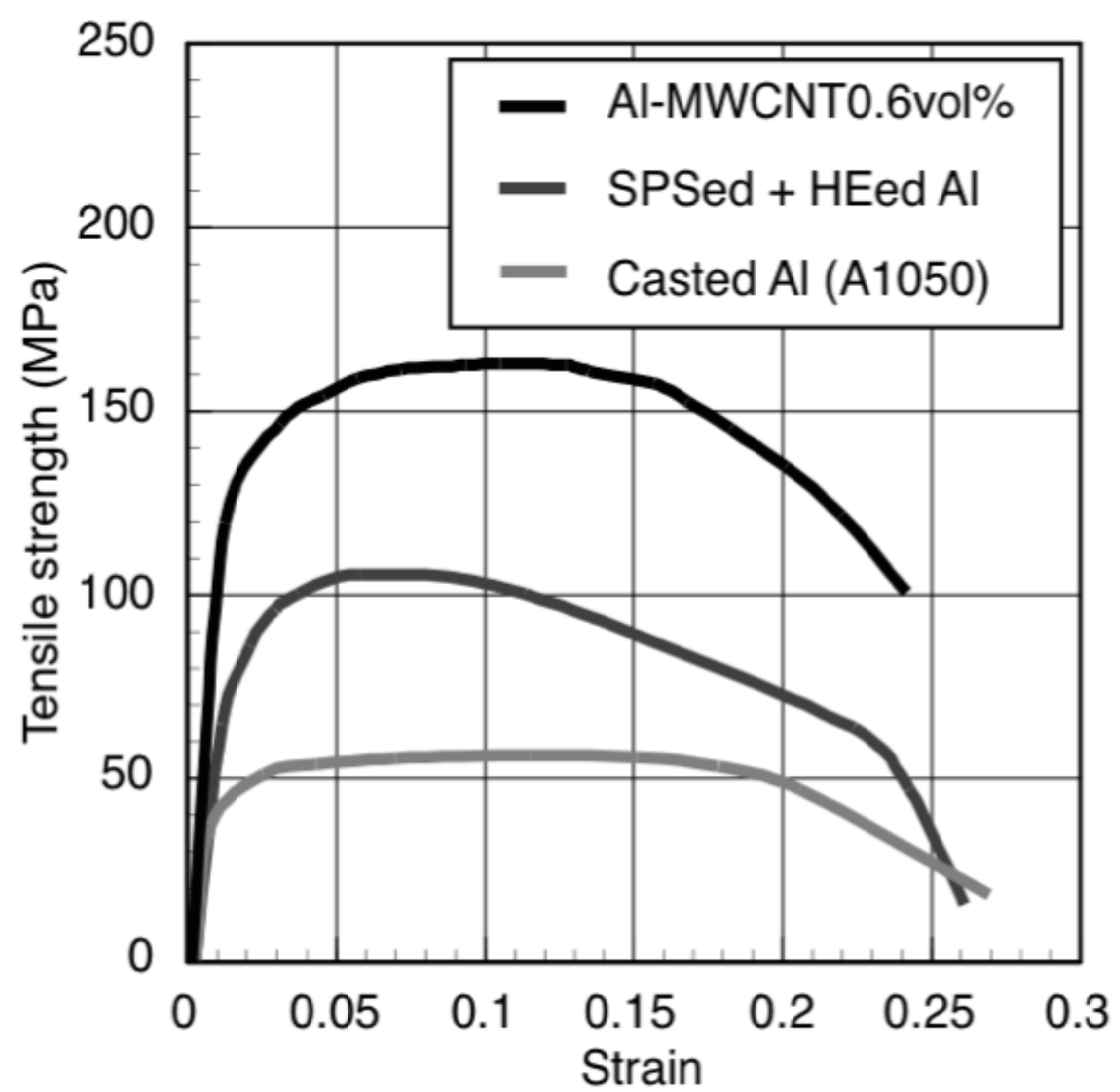




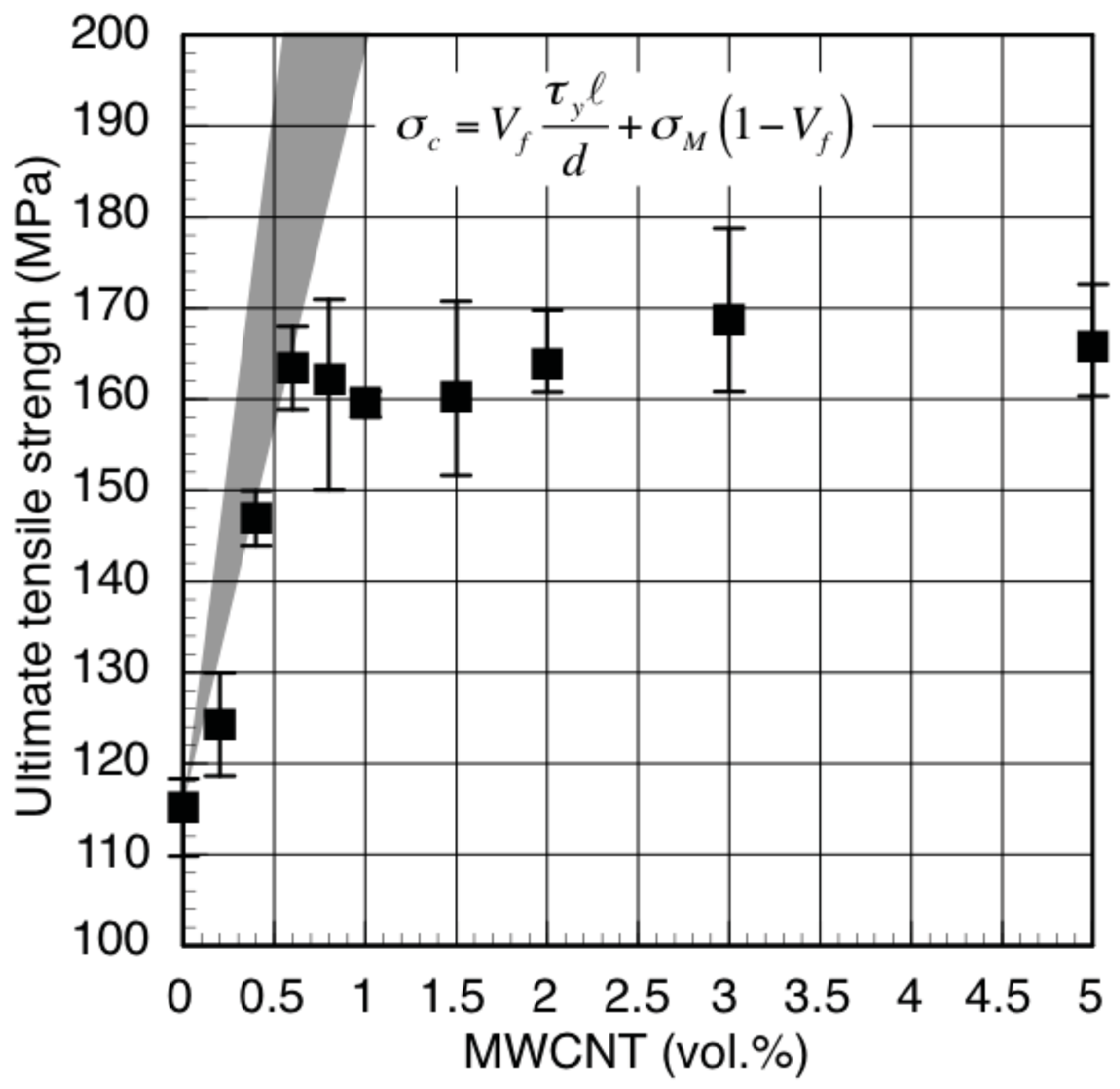



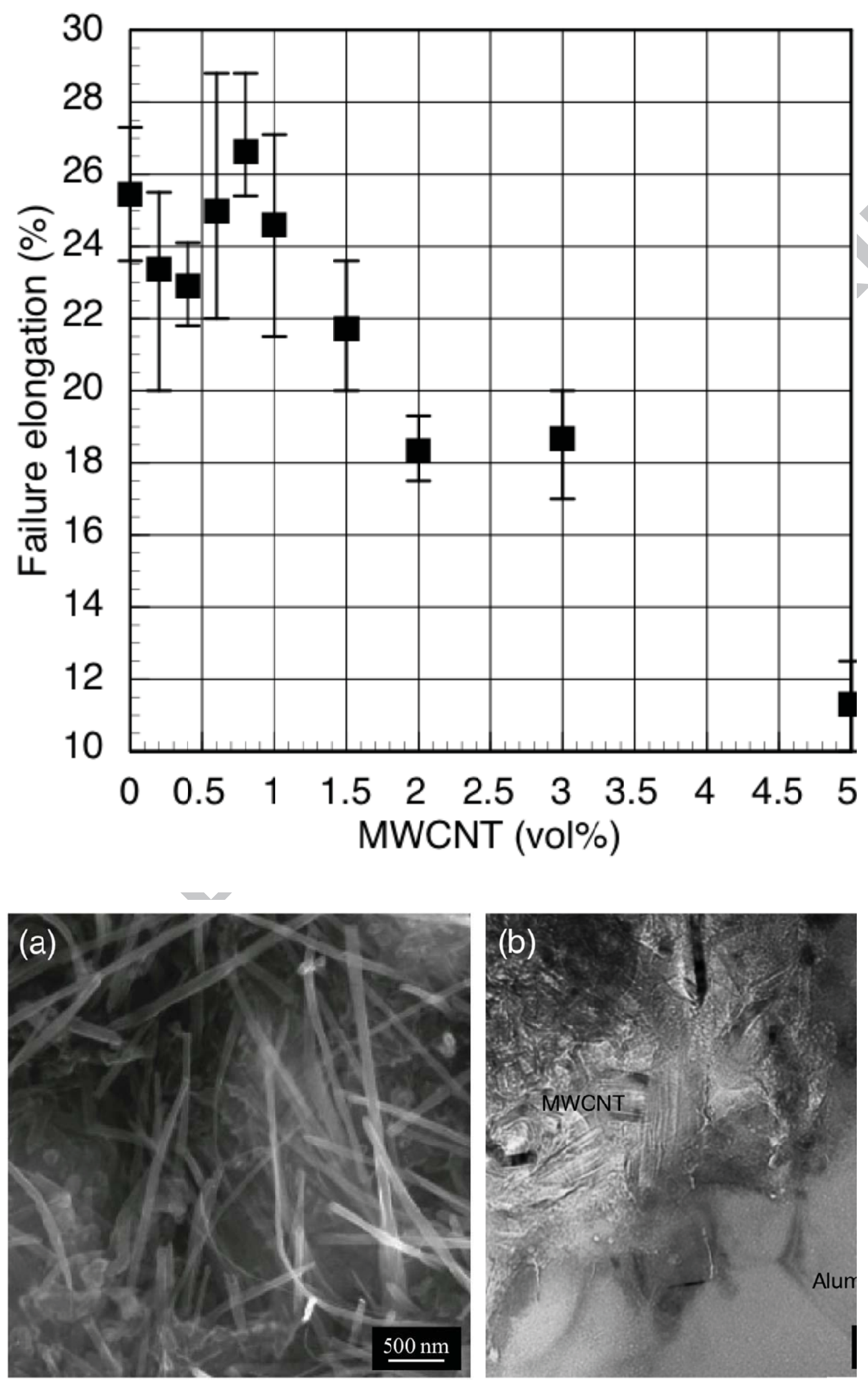
Table 1. Relative densities of Al-MWCNT composites fabricated by SPS, and SPS followed by hot extrusion.

\begin{tabular}{ccc}
\hline MWCNT, vol.\% & $\begin{array}{l}\text { Relative density of } \\
\text { spark plasma sintered bulk, \% }\end{array}$ & $\begin{array}{c}\text { Relative density of } \\
\text { hot extruded bulk, \% }\end{array}$ \\
\hline 0,0 & 99,7 & 99,9 \\
0,2 & 99,5 & 99,9 \\
0,4 & 99,4 & 99,9 \\
0,6 & 99,3 & 99,9 \\
0,8 & 99,3 & 99,9 \\
1,0 & 99,1 & 99,9 \\
1,5 & 98,8 & 99,9 \\
2,0 & 98,3 & 99,9 \\
3,0 & 98,0 & 99,9 \\
5,0 & 97,5 & 99,9 \\
\hline
\end{tabular}


Keywords: A. Metal-matrix composites (MMCs); B. Mechanical properties; E. Extrusion; E. Powder processing 